Paideusis

\title{
A Review of Kieran Egan's The Educated Mind: How Cognitive Tools Shape Our Understanding
}

\section{M.E. Michelle Forrest}

Volume 12, Number 1, 1998

URI: https://id.erudit.org/iderudit/1073096ar

DOI: https://doi.org/10.7202/1073096ar

See table of contents

Publisher(s)

Canadian Philosophy of Education Society

ISSN

0838-4517 (print)

1916-0348 (digital)

Explore this journal

Cite this document

Forrest, M. (1998). A Review of Kieran Egan's The Educated Mind: How

Cognitive Tools Shape Our Understanding. Paideusis, 12(1), 49-59.

https://doi.org/10.7202/1073096ar

This document is protected by copyright law. Use of the services of Erudit (including reproduction) is subject to its terms and conditions, which can be viewed online.

https://apropos.erudit.org/en/users/policy-on-use/ 


\title{
Critical Discussion
}

\section{A Review of Kieran Egan's The Educated Mind: How Cognitive Tools Shape Our Understanding ${ }^{1}$}

\author{
M. E. Michelle Forrest, Acadia University
}

Kieran Egan offers a book of wide erudition, expansive theory, and intriguing particulars. His speculation on the workings (he calls them "tools") of human understanding ranges across a variety of lines of thought from different discourses. Egan begins from the assumption that we are in a period of educational crisis and he uses the example of the economic crisis in 17th century Europe to make his point that incremental change in the particulars of a situation is fruitless if what is needed is a shift in the general theory of how it ought to be perceived. His purpose is to offer a "new idea." He claims that first we need to reassess the dominant educational theory, what he calls the "three old ideas"-education as socialisation, as accessing a transcendent conversation, and as facilitating the natural development of the learner. Egan's main objection to the old ideas is that they are incompatible. The transcendent cultural conversation of the Platonic or rationalist idea of education encourages a critical attitude towards the content of knowledge which is at odds with the "homogenizing aim" of education as socialisation. The Platonic idea of initiating the learner into the forms of knowledge is not compatible with the Rousseau-ian focus on learner development. The primacy of society's norms and values in the socialising model conflicts with Rousseau's injunction to follow the path traced by the natural development of the learner. ${ }^{2}$ Egan allows that, in practice, no one of the ideas is adhered to exclusively. Teachers try to balance their competing claims and needs. He sees this as a formula for failure. Describing the "compromise between incompatibles" from the point of view of the progressivists, Egan says:

they feel it is important to "expose" students to the "high culture" curriculum content but they feel no imperative to persist with it for students who do not take to it. That is, each idea is allowed scope enough to undercut the other. ${ }^{3}$

From Egan's perspective, the situation is grim. "At best," he says "schooling is a set of flaccid compromises among these three great and powerful ideas." 4

In addition to this charge, Egan frequently expresses his distaste for the commonly held notion of "relevance" in education and attributes it to the "progressivist program."5 "Relevance" is the focus of Egan's 1991 article "Relevance and the Romantic Imagination" 6 in which he tells of a beginning teacher who after weeks of research for "relevant" materials on the Middle Ages uncovered only the fact that during this period women's high-heel shoes were invented. Egan makes the point that this literal interpretation of relevance, one requiring a concrete relation between personal experience and curricular materials, excludes the imagination as part of everyday experience. He says:

It is a widespread belief that students will more readily learn and understand material if it is made relevant to their everyday experience. This truism is commonly interpreted to exclude students' imaginative life as an element of everyday experience? 
Egan points out that relating curricular materials to the life of the imagination is in keeping with one of Dewey's pervasive themes-his insistence that the object of study "be derived from materials which at the outset fall within the scope of ordinary life experience."8 It is not difficult to imagine that an inner life may exist without benefit of formal schooling. Indeed, schooling is taken by some as imagination's greatest threat.

From these earlier thoughts on relevance, it would seem the "progressivist program" to which Egan attributes the literalist notion of relevance is not Dewey's progressivism. It would help if Egan were to describe in more detail the particular interpretation of progressivism to which he attributes the literalist notion of relevance. 10 As for the term "relevance" and whether Egan considers it irrelevant to set relevance as a goal or value in education, it is curious to note how he uses the term in speaking of the critique of the Western canon. He says:

In this century, we, the masses, have become more or less literate and are equipped to access the accumulated lore of the Western tradition. A crucial problem for the school curriculum and increasingly for the college and university curriculum has, thus, become the relevance of that quondam elite culture to the lives of the masses. ${ }^{11}$

By "quondom elite," Egan could mean a culture that, though unchanged in character, has lost the status befitting its character. However, considering he calls himself one of the masses, it appears he means that an elite culture no longer exists. In either case, there is the suggestion that such a group is a cultural entity. The notion of an elite culture might also be read as the convenient myth of a self-proclaimed master-group whose dominance is maintained by propagating its definition of itself as ideal and universal by means of a canon of required readings and appropriate responses. On the other hand, Egan may be being ironic when he calls himself one of the masses.

Egan characterises his "new idea" as stemming from two lines of thought: a version of recapitulation theory and Vygotsky's notion of the "intellectual tool." He attempts to distinguish his version of recapitulation from its forbears according to that which one identifies as being recapitulated in every learning process. He rejects a version of recapitulation which attempts to take the learner through the logical order of knowledge as it is thought to have developed in cultural history and he rejects the psychological version based on the attempt to identify a common psychological basis to cultural and individual development. Rather, drawing from Vygotsky, Egan sees the process of recapitulation playing itself out in the development of the learner's "mediating intellectual tools" (a phrase Egan uses interchangeably with "sign systems"12), the implications of which he calls "kinds of understanding"13 of which he identifies five. Mythic understanding includes "abstract and affective binary opposites, metaphor, images and story-structuring."14 Romantic understanding is characterised by

a fascination with the limits of reality and the extremes of experience; a ready engagement by knowledge represented as a product of human emotions and intentions; and a detailed interest in something. ${ }^{15}$

Philosophic includes:

the formation of general schemes and a language of theoretic abstractions to support them; the sense of oneself as an agent (or, more fashionably, a 
victim) within complex social, psychological, metaphysical, and historical processes; the lure of certainty; the search for authority and truth with general schemes; the dialectical play between general schemes and anomalies; and the flexibility theory gives to the mind's ability to deal with the world. ${ }^{16}$

Egan calls Ironic understanding a "more inclusive irony" which involves "sufficient mental flexibility to recognize how inadequately flexible are our minds, and the languages we use, to the world we try to represent in them. Ironic really." 17 Lastly, he describes Somatic understanding as "a general embodied kind of understanding that is somewhat distinct from the languaged and conceptual kinds discussed so far." He says it is most evident in "pre-language-using human experience" though ideally "it remains with us throughout our lives, continuing to develop within, though somewhat kinds of understanding. ${ }^{18}$

Egan characterises a "kind of understanding" by its "set of intellectual tools" as manifest in language use, yet he says that Somatic understanding is distinct from the other "languaged and conceptual kinds." One might ask how a kind of understanding characterised by language development ${ }^{19} \mathrm{can}$ be recognised in one who is "prelanguage-using"? Though Egan admits that he has little to say about Somatic understanding as a distinctive kind, he claims that it has a persisting presence in Ironic understanding. ${ }^{20}$

One of the conventions of theorising is the practice of describing a current theory, typically one which the theorist would like to change because of its effects or lack thereof. Egan begins in this way, citing the crisis of education as an obvious ill and claiming it is at least partly the effect of the incompatibility of existing theories. There are three assumptions in Egan's theorising that require scrutiny: that things are as they appear or as they are represented (that is, there is a crisis in education), that this crisis effect is the result of theory, and that incompatibility among theories is necessarily a bad thing.

Is it not possible that part of the tenor of our times is the perception that we are in crisis? How has this perception arisen? Heidegger asks concerning the pervasiveness of a world picture:

Does every period of history have its world picture, and indeed in such a way as to concern itself from time to time about that world picture? Or is this, after all, only a modern kind of representing, this asking concerning a world picture? ${ }^{21}$

Though one needs to ask "Is education in crisis?", one also needs to ask whether the perception of a world in crisis is a convention of our times-the way we represent ourselves to ourselves. The difficulties of representation--How do I represent the world to myself? What is the role of this representing process in my understanding?-are bound up in questions about the epistemological status of knowledge claims. In his discussion of Ironic understanding, Egan takes this up, but does not turn it upon his own argument in a typical postmodern gesture.

In his discussion of irony, ${ }^{22}$ Egan begins from Dr. Johnson's definition ("A mode of speech in which the meaning is contrary to the words") 23 and eventually arrives at Schlegel's concept of irony as "the clear consciousness of an infinitely teeming chaos." 24 Egan appears to continue from this point assuming that irony is synonymous with scepticism. One may demonstrate radical epistemic doubt (that is, a consciousness of the "teeming chaos") by means of 
an ironic gesture, but to assume that irony necessarily cuts this deep is to lose the distinction between it and scepticism. ${ }^{25}$ Conversely, one need not be a sceptic to use irony in raising doubt regarding the existence of absolute truth.

Egan says that Ironic understanding "avoids commitment to the credulity common in Philosophic understanding but also avoids commitment to the incredulity common in postmodernism." What I would suggest is missing from his account of postmodernism is its distinctive gesture: the ironic turn. Egan begins his chapter on ironic understanding by considering the proposition "all generalisations are false" which he says is self-refuting. The charge commonly levelled against postmodernism is that it is a form of relativism; it rejects metanarratives, thus refuting itself. But as Rorty points out, "[t]o accuse postmodernism of relativism is to try to put a meta-narrative in the postmodernist's mouth. 27 There is a difference between saying "all meta-narratives are false" and adopting a sceptical attitude and methodology regarding meta-narratives. As Egan admits, "even a postmodernist will accept the use of intellectual capacities that generate meta-narratives; the crunch comes in claims about the epistemological status of their products. ${ }^{28}$

It is my understanding of postmodernism as a philosophical project that, in order to keep this scepticism alive and obvious, one demonstrates it by means of an ironic gesture. For example, were I to follow what I have just said with the statement "What I have just said is false," I would be refuting my initial statement and would need to bring evidence to bear upon my claim in order to justify it. This is the usual course of logical reasoning and argumentation. If, instead, I were to follow my opener with "What I have just said is false because all generalisations are false," I would be using irony. ${ }^{29}$ This I take to be a typically postmodern move. ${ }^{30}$ Derrida calls it a double gesture or double play which is "marked in certain decisive places by an erasure which allows what it obliterates to be read." 31 My comment about my own statement demonstrates verbal irony in that what I say is so refutes itself. It also demonstrates what I call ontological irony since my verbal irony is directed at the very nature of claims about truth. ${ }^{32}$ The duplicity of the postmodern gesture is what saves it from the charge of relativism.

Egan assumes that postmodernism rests upon the self-refuting claim "all claims to absolute truth are false." But there is more (or less) to the postmodern gesture than meets the "I".33 The double gesture claims nothing. It disclaims its own act of proclamation. Egan's move of trying to "put a meta-narrative into the postmodernist's mouth" does not address the postmodern critique of reason because he assumes the critique plays by the rationalist's rules. For the postmodemist, the rules of play can change because the grounds upon which they are played are uncertain. While Egan wins at his own game, the postmodern strategy changes as it goes. One feels rather like Alice at the Queen's croquet-ground:

"I don't think they play at all fairly," Alice began, in rather a complaining tone, "and they all quarrel so dreadfully one can't hear oneself speak and they don't seem to have any rules in particular; at least, if there are, nobody attends to them and you've no idea how confusing it is all the things being alive; for instance, there's the arch I've got to go through next walking about at the other end of the ground and I should have croqueted the Queen's hedgehog just now, only it ran away when it saw mine coming!" 34 
On waking up and discovering she was shaking the kitten instead of the Queen of Hearts, Alice was annoyed that the cat wouldn't answer her questions. It merely purred and purred:

But how can you talk with a person if they always say the same thing?" she wondered. ${ }^{35}$

This brings me to Egan's second assumption: that the educational crisis is the effect of theorising. Writers often critique a theory or philosophy of education based upon the charge that in practice it does not live up to its claims. This charge is implicit in the comments of pre-service teachers disgruntled that the fine and noble theories they read and talk about in their B.Ed. courses do not work in the "real" world. The problem with this charge, which on its face is easy to accept, is that it assumes that theory can be transferred or, as everyday speech phrases it, "put into practice." Hirst describes the relationship of theorising to practice it this way:

[T]he disciplines we have deal with certain aspects abstracted from complex practical situations, dealing with these in dissociation from each other. There is no reason whatever to suppose that these abstractions when put together begin to give any adequate understanding of the situation for practical purposes, nor even that they ever could.

He goes so far as to say that "the very character of the disciplines seems such that they must prove inadequate as a basis for practical principles . . . [E]ach tackles questions which are peculiar to itself, those that can be raised only within its own distinctive conceptual apparatus. ${ }^{36}$

If theory is inadequate as a basis for practice, what use is it? Would it be better, as some contend, for students to become apprentices to classroom teachers, learning as they go from those working where they intend to work? According to Hirst, the disciplines do have a contribution to make to practice:

Psychologists, sociologists or philosophers faced with any matter of practical policy on, say, the grouping of pupils in schools or the use of punishment, can legitimately comment only on different psychological, sociological or philosophical issues that may be at stake. ${ }^{37}$

Hirst is also helpful in pointing out an overlooked distinction between successful practice and justifiable practice. The two are not necessarily synonymous unless one considers success to be a justification in and of itself. Even if the educational crisis Egan describes were to disappear, this would not necessarily mean that the educational practice which ended the crisis was justifiable. For example, it is conceivable that everyone could succeed at school if we were to do away with testing, but would we consider this justifiable?

The assumption that theory is directly transferable into practice is also implicated in Egan's third assumption: that incompatibility among theories is necessarily a bad thing for educational practice. I have always considered it a strength of education as an enterprise that its divergent assumptions continue to be articulated in educational debate. The idea that any group might reach consensus regarding educational priorities seems more the basis for indoctrination than for education. Life results in conflicting needs, desires, and interests. The fact that educational enterprises reflect this divergence seems altogether appropriate. I am not, however, one of those whom Egan depicts as arguing for competing ideas simply as "necessary tensions" produced by the competition of 
"stakeholders."38 Egan's choice of language here implies the argument for incompatibility rests upon a veiled argument from fairness. In and of itself, this would not justify the continuation of that which makes more complex an already difficult undertaking. The reason the so-called "old ideas" retain a certain purchase in educational debate is because each places its emphasis upon a different aspect of the educational contract: the Platonic tradition stresses the importance of critically assessing received ideas; progressivists begin from a recognition of the individual learner and her responses to her environment; and the socialisation idea, with its roots in nineteenth-century utilitarianism, focuses educational thought upon the need to reproduce social conventions for the sake of continuity and predictability. Each of these ideas acts as a check on the priorities of the others. Without a recognition of the significance of the lived experience of the learner, socialisation can become a regime of rote learning and mindless subservience. The idea of beginning from individual experience can easily assume the metaphor of learner as blank slate or empty vessel, an assumption which needs to be tempered by the reminder that no one begins from nowhere - that is, that we are born into a set of pre-inscribed conventions, traditions, beliefs, and assumptions. The Platonic ideal of learning the forms within which we have traditionally conversed and proceeded and, then, rationally establishing a critical distance from them is tempered by a recognition that traditional discourses, even when engaged in critically, can serve to silence those who are not among the initiates.

Though I see no necessary ill from these incompatibilities, I am also willing to entertain the possibility that there is a better starting place. Has Egan found it? His notion that we ought to begin from the idea of education as a process of developing cognitive or intellectual tools is a slippery one. It is not until the afterword to his book that Egan states most clearly his conception of recapitulation and its relationship to his "kinds of understanding." He says:

We begin with the Somatic and Mythic kinds, whose basic forms are genetically programmed as a result of our evolutionary history; they come with the human body, in its senses and brain, and with the development of an oral language. Thereafter our general learning capacity comes increasingly into play, enabling us, more laboriously, to develop Romantic, Philosophic and Ironic kinds of understanding by recapitulating the cultural inventions of literacy, theoretic thinking, and extreme linguistic reflexiveness. ${ }^{39}$

With the notion of "intellectual mediating tool," Egan attempts to posit outside the learner that which is measurable as being recapitulated. He claims to have avoided the old versions with their focus on the biological and the psychological. Yet, he claims that the two basic kinds are genetically programmed by our evolutionary history, and he speaks of "our general learning capacity" which he says gradually takes over around the ages of five to eight from the urgent "dynamic language-learning and society-orienting drives. ${ }^{40}$ This talk of drives and a leaming capacity in conjunction with the claim that the "kinds" are genetically programmed would seem to fix his theory in human biology and psychology.

Though Egan appears to move from a cognitive to a cultural grounding for a theory of education, he does not succeed, it seems to me, because the crux of his idea, the cognitive or intellectual tool, is not sufficiently articulated. In a 
chapter devoted to a fictional question-and-answer session, he says he begins from the assumption that "human minds everywhere are pretty much the same" and goes on to say that the differences in the way people make sense of the world stem "mainly from the various intellectual tools they are deploying rather than from their genetic makeup." His imaginary sceptical reader takes exception to Egan's use of vague terms and phrases such as "pretty much," "general differences," and "mainly." He replies:

[T] he differences we note in people's thinking are sufficiently accounted for by differences in the intellectual tools being used. There may be differences because of age, gender, race, or whatever, but even if there were, these seem less useful in characterizing kinds of understanding compared with the influence of the cognitive tools I have been considering. ${ }^{41}$

The questioner then speaks for developmental psychologists asking again about the implication that age is not significant in the development of kinds of understanding. Egan says it is not that age has no influence but that it is very difficult, if not impossible, to assess apart from the child's socio-cultural context. The questioner wonders whether Egan does not have the process the wrong way around, that surely language developments are a function of maturation. Egan offers the counter-example of those in some cultures for whom maturation does not bring language development and says:

What makes this theory interesting is its elaboration of a category-kinds of understanding - that is, distinct from the psychological and epistemological categories we have been accustomed to use for cultural and educational development. This new category incorporates the influences of psychology and epistemology but does not try to separate them out. ${ }^{42}$

If, as Egan claims, his "kinds" are not a category in a theory of cognition nor in a theory of knowledge, what kind of category is he offering? If it is a hybrid of the two, then he needs to articulate, in more than passing references to the work of other theorists, just how this category is justifiable as such. ${ }^{43}$ I find nothing to ground his "'kinds" as an epistemological category. Egan uses the term "understanding" with no developed reference to the classic works on the mind and thought such as those of Gilbert Ryle and Alfred North Whitehead. In fact, he seems to labour under the very category mistake Ryle articulated in The Concept of Mind conceiving mind as a different sort of thing from body, but a thing nonetheless, one that is reflected in the things people say and do. In exploding the myth of mind as ghost in the machine, Ryle claims that "the styles and procedures of people's activities are the way their minds work and are not merely imperfect reflections of the postulated secret processes which were supposed to be the workings of minds." 44

One might object that in focusing on cognitive tools, Egan does recognise that styles and procedures are the workings of mind. But one need only recall that he says sets of intellectual tools "characterise" kinds of understanding and, conversely, that intellectual tools are "implications from" kinds of understanding. Were Egan to go all the way with his thesis regarding the importance of these tools calling them understanding itself, he would be faced with the prospect he is unwilling to entertain-namely, that we are languaged beings completely with no recourse to universally applicable knowledge claims other, that is, than those we construct for summarising our propositions. ${ }^{45}$ It seems 
that Egan wants to have his cake and eat it, too: he wants to use language as his measure while clinging to a universalist notion of truth which would disappear if language really were the measure. ${ }^{46}$ Though Egan was influenced by Whitehead's stage of romance in his theory of education as a three-part rhythm, ${ }^{47}$ he seems not to have considered Whitehead's thoughts on understanding. In Modes of Thought, he begins his discussion of understanding by pointing out a common fallacy in talk about intelligence and understanding:

We can enlighten fragmentary aspects of intelligence. But there is always an understanding beyond our area of comprehension. The reason is that the notion of intelligence in pure abstraction from things understood is a myth. Thus a complete understanding is a perfect grasp of the universe in its totality. We are finite beings; and such a grasp is denied to us. ${ }^{48}$

He goes on to say that "self-evidence is understanding." 49 This brings me back to an earlier point: that one is caught in the difficulties of representation. What appears self-evident is inevitably bound up in how one represents the world to the self. If I am to turn Whitehead's reminder of the frailty of human understanding against Egan's theory of "kinds," I must also turn it against myself. Is it that Egan has failed to successfully articulate the basis of his theory, or that I have failed to draw out the necessary points to satisfy my own standards of justification?

In his descriptions of how teachers might enliven and "make relevant" curricular materials, Egan is at his best and, for this alone, the book is worth reading. ${ }^{50}$ He has me believing that either he taught ancient and medieval history or was himself an avid student of a lively history teacher. At any rate, I am left wishing $I$ had been in his class. After all is said and done about his theorising in education, what greater recommendation could a new theory get than that it recreated in print a feeling of "classroom."

This account has focused on what Egan holds to be the basic concepts of his theory. I have raised more questions than I have answered and have barely touched on the particulars of the "kinds" themselves. But to focus on the many strengths of those analyses without asking the larger questions regarding the framework into which he has placed them would not be appropriate, it seems to me, for a critical review in a journal of philosophy of education. When I referred earlier to Paul Hirst on the nature of educational theory, the reader may have made the connection to his "forms of knowledge," a thesis which generated no end of critiques and responses throughout the $1970 \mathrm{~s}$. In fact, the shift in his thinking about educational theory in the direction of an operational model,-that is, one grounded in a consideration of current practice as manifest in its discourse-was doubtless spurred on by critics who took his theory as representative of everything oppressive in traditional pedagogical practice. ${ }^{51} \mathrm{~A}$ comparison between Hirst's "forms" and Egan's "kinds" could make for an interesting study since both ground their concept in language but in very different ways. I can only wish for Egan a smoother ride with fewer misinterpreters than Hirst had. For myself, I hope not to be one of those who got it wrong. 


\section{Notes}

${ }^{1}$ Kieran Egan, The Educated Mind. How Cognitive Tools Shape Our Understanding, (Chicago: University of Chicago, 1997), 299pp.

2Egan, 1997, 10-22.

3Egan, 1997, 23.

${ }^{4}$ Egan, 1997, 24.

${ }^{5}$ Egan, 1997, 238.

6Kieran Egan, "Relevance and the Romantic Imagination," Canadian Journal of Education, 16(1), 1991.

${ }^{7}$ Egan, 1991, 58.

${ }^{8}$ Egan, 1991, 59, from John Dewey, Experience and Education (New York: Macmillan, 1938), 86.

${ }^{9}$ Egan, 1997, 238.

${ }^{10}$ In his overview of the pragmatic tradition in philosophy of education, Joe Park distinguishes three camps of the progressive-education movement. The Dewey camp or "sober wing" placed more emphasis on reflection and subject matter than did the second camp who were more child-centered and activityoriented. The third camp are the reconstructionists who formed at the time of the Depression and were concerned primarily with social issues. See Selected Readings in Philosophy of Education (2nd ed.), edited by Joe Park (New York: Macmillan, 1963), 68-69.) As Dewey makes clear in Experience and Education (1938), many of his self-proclaimed followers misinterpreted or misunderstood his ideas.

${ }^{11}$ Egan, 1997, 205. Does Egan's use of the Latin adverb "quondam" (that once had but no longer has the specified character, sometime, former (OED) strike the reader as it struck me? As ironic? Who but a member of the quondam elite culture would use the work "quondam"?

${ }^{12}$ Egan, 1997, 29.

${ }^{13}$ Egan, 1997, 31.

${ }^{14}$ Egan, 1997, 244.

${ }^{15}$ Egan, 1997, 254.

${ }^{16}$ Egan, 1997, 263-264. Note Egan's parenthetical remark. It is one of many such ironic asides throughout the text.

${ }^{17}$ Egan, 1997, 155.

${ }^{18}$ Egan, 1997, 162-163

${ }^{19}$ Egan, 1997, 262: "This theory is largely about language developments, not so much in terms of vocabulary growth and grammatical sophistication-though they obviously play a role-but in terms of the kinds of concepts, the focus of discourse, the everyday content that surround and seek responses from the child."

${ }^{20}$ Egan, 1997, 162.

${ }^{21}$ Martin Heidegger, "The Age of the World Picture," The Question Concerning Technology and Other Essays, William Lovitt, trans. (New York: Garland, 1977), 128-129.

${ }^{22}$ Egan's discussion of irony is full of both known and obscure references deftly handled. In my estimation, this chapter alone makes the book worth reading.

${ }^{23}$ Egan, 1997, 139. 
${ }^{24}$ Egan, $1997,146$.

${ }^{25}$ It should be noted that my comments are not directed at Schlegel's concept of irony, but rather at the use Egan makes of it.

${ }^{26}$ Egan, 1997, 156.

${ }^{27}$ Richard Rorty, "Postmodernist Bourgeois Liberalism" (1993), Postmodernism. A Reader, Thomas Docherty, ed. (New York: Columbia University Press), 1993, 328.

${ }^{28}$ Egan, 1997, 156.

${ }^{29}$ Egan, 1997, 156.

${ }^{30}$ The classic gesture of this kind is that which Derrida uses at the beginning of "Outwork," the preface to Dissemination: "This (therefore) will not have been a book." (See Jacques Derrida, Dissemination (1972), Barbara Johnson, trans. (Chicago: University of Chicago, 1981), 3). Barbara Johnson explains in her introduction that Derrida takes the convention of the preface "written after to stand before the beginning" as exemplar for the illusion that theoretical discourse is ever not "belated and precipitous with respect to the textual practice it attempts to comprehend" (xxxii).

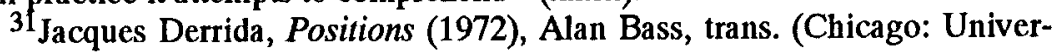
sity of Chicago, 1981), 6.

${ }^{32}$ For a more detailed discussion of Derrida's double gesture and its pedagogical implications, see my "no ordinary chaos" in Heuretics for Media Work in Education (Unpublished doctoral dissertation, Halifax: Dalhousie University, 1997), 154-171.

${ }^{33}$ As with any "-ism," there are many interpretations. It seems to me that "strong" postmodern exposition continually attempts to undercut its own assumptions, which is not to say that it rejects rationality. Instead of composing, it decomposes. For an account of the pedagogical implication of Derrida's decomposition, see Gregory Ulmer, Applied Grammatology: Post(e)-Pedagogy from Derrida to Joseph Beuys (Baltimore and London: The John Hopkins University Press, 1985).

${ }^{34}$ Lewis Carroll, Alice in Wonderland (1923) (New York: Holt, Rinehart and Winston, 1961), 79.

${ }^{35}$ Carroll, 1923, 273.

${ }^{36}$ Paul Hirst, Educational Theory and its Foundation Disciplines, Paul Hirst, ed. (London: Routledge \& Kegan Paul, 1983), 6-7.

${ }^{37}$ Hirst, 1983, 6.

${ }^{38}$ Egan, 1997, 206.

${ }^{39}$ Egan, 1997, 277.

${ }^{40}$ Egan, 1997, 278.

${ }^{41}$ Egan, 1997, 173-174.

42Egan, $1997,174$.

${ }^{43}$ It is possible that Egan does lay the proper groundwork but that my knowledge of his previous work or of the sources to whom he refers is not sufficient to grasp the larger picture. However, even if this were the case, it seems to me that the logic of his justification ought to have been included in this work.

${ }^{44}$ Gilbert Ryle, The Concept of Mind (Middlesex: Penguin, 1949/1980).

${ }^{45}$ Rorty makes the point that Hegelians do not completely repudiate Kan- 
tian ahistorical and transcultural principles. They see them as useful for summarising their hopes, but not for justifying them. See Rorty, "Postmodernist Bourgeois Liberalism," 325.

"S6andra Harding uses the term "universalist" to refer to those who believe in knowledge claims with universal applicability. See "Rethinking Standpoint Epistemology," Feminist Epistemologies, Linda Alcoff and Elizabeth Potter, eds. (New York: Routledge, 1993).

${ }^{47}$ Alfred North Whitehead, The Aims of Education and Other Essays (New York: the Free Press, 1929/1967).

${ }^{48}$ Alfred North Whitehead, Modes of Thought (New York: The Free Press, 1938/1966), 42.

${ }^{49}$ Whitehead, 1938, 47.

${ }^{50} \mathrm{~A}$ visit to Egan's website reinforced my sense that despite the logical failings of this theory, assuming my observations are valid, it has an immediate appeal to practitioners who, like Egan, are frustrated by limited notions of what it means to make something "relevant" to students" everyday lives. It is also interesting to note the difference in tone between the Egan who is theorising and the Egan who is answering his correspondence. In the latter, there is no hint of the glib and sometimes scathing tone which regularly creep into his book. For example, there is his playful concession to an imaginary prompt from the reader to list the rank of angels in his discussion of hierarchy (119), and the parenthetical addition of the term "victim" in the quotation cited earlier (fn. 17).

${ }^{51}$ See Paul Hirst, Knowledge and the Curriculum (London: Routledge \& Kegan Paul, 1974) and, for one of the most noteworthy critiques, see Jane Roland Martin, "Needed: A New Paradigm for Liberal Education," Yearbook of the National Society for the Study of Education, J.F. Soltis, ed., 1981. 